\title{
Battling Inflammation in Acute Lung Injury and Acute Respiratory Distress Syndrome: Stem Cell-Based Therapy Targeting the Root Cause of Acute Lung Injury
}

\author{
Ryan W. Bonvillain ${ }^{1}$, Shijia Zhang ${ }^{1,2}$, Michelle E. Eagle ${ }^{1}$, Svitlana Danchuk ${ }^{1,3}$, Bruce A. Bunnell ${ }^{1,2}$ and Deborah E.Sullivan ${ }^{1,3,4 *}$
}

${ }^{1}$ Center for Stem Cell Research and Regenerative Medicine, Tulane University, School of Medicine, New Orleans, LA 70112, USA

${ }^{2}$ Department of Pharmacology, Tulane University, School of Medicine, New Orleans, LA 70112, USA

${ }^{3}$ Section of Pulmonary Diseases, Critical Care, and Environmental Medicine, Tulane University, School of Medicine, New Orleans, LA 70112, USA

${ }^{4}$ Department of Microbiology and Immunology, Tulane University, School of Medicine, New Orleans, LA 70112, USA

\begin{abstract}
Acute lung injury (ALI) describes one or more initiating assaults either directly to the lungs or systemically that, if not treated in a timely manner, ultimately progresses to the development of acute respiratory distress syndrome (ARDS) a condition which is characterized by atelectasis, pulmonary hypertension, and an intense, overwhelming inflammatory response that leads to obliterating pulmonary fibrosis and ultimately respiratory failure. The long-term complications associated with ALI/ARDS can be subverted if the fibrotic phase of the disease is suppressed; therefore, it is essential to control inflammation in such a way that endogenous self-protection mechanisms are maintained while not allowing escalating inflammatory damage to occur in the local environment of the lungs. Current treatment strategies focus on optimal ventilator management and treatment of the underlying condition. Cell-based approaches are an attractive option for directed therapeutic intervention for ALI/ARDS. In particular, mesenchymal stem cells (MSCs) from bone marrow, adipose, umbilical cord, and lung tissue as well as induced pluripotent stem (iPS) cells have been shown to facilitate lung repair in several animal models of ALI. The exact mechanism(s) by which these cells accomplish this feat are as yet unknown; however, mounting evidence suggests that they possess potent immunomodulatory and antimicrobial capabilities which diminish the injury-induced inflammatory responses and reduce infection-mediated ALI, respectively, in these various models. Both direct delivery of stem cells to the lung and systemic administration have been somewhat effective, suggesting that stem cells utilize paracrine mechanisms, at least in part, to perform these functions. Aside from their endogenous ability to suppress inflammation and infection, gene-modified MSCs and iPS cells have recently been used as vehicles for carrying anti-inflammatory agents to the lung. Taken together, stem cell therapy is a promising alternative to current therapeutic intervention for ALI/ARDS.
\end{abstract}

Keywords: Inflammation; Lung; Acute Lung Injury; Acute Respiratory Distress Syndrome; Stem Cells; Mesenchymal Stem Cells; Cell Therapy

\section{Introduction}

Acute respiratory distress syndrome (ARDS) is characterized by a serious, life-threatening onset of respiratory failure initiated by a myriad of assaults that lead to massive localized pulmonary inflammation- a condition collectively referred to as acute lung injury (ALI). Clinically, the criteria for defining ALI include respiratory failure with a $\mathrm{PaO}_{2} /$ $\mathrm{FiO}_{2}$ ratio $\leq 300 \mathrm{mmHg}$ regardless of positive end expiratory pressure (PEEP), pulmonary vascular wedge pressure $<18 \mathrm{mmHg}$ or normal left atrial filling pressure, bilateral infiltrates (inflammatory cells) on chest radiograph, and acute onset of respiratory failure with pulmonary inflammation and increased capillary permeability; ARDS is defined by the same criteria as ALI except with a measure of a reduced limiting value of $<200 \mathrm{mmHg}$ for $\mathrm{PaO}_{2} / \mathrm{FiO}_{2}$ [1]. Lung injury scoring has been used as a supplement to the above criteria for defining ALI/ARDS, taking into account diffuse alveolar damage (DAD) and oxygenation measurements influenced by PEEP [2-8]. ALI can be initiated directly by bacterial or viral infection, aspiration of gastric contents, aspiration of meconium in utero, blunt thoracic trauma involving lung, near-drowning, hyperoxia, irritant or toxicant inhalation, disseminated intravascular coagulation (DIC), and thoracic radiation. Other pathologies can indirectly lead to ALI; these include bacteremia (sepsis), hypovolemic shock, distant-site (non-thoracic) trauma, closed-space burn injury, and pancreatitis [9-14]. Ironically, clinical intervention for disease, including some of the aforementioned conditions, can also initiate the onset of ALI. Additionally, repeated transfusion, cardiopulmonary bypass, and ventilatory support have all been associated with development of ALI and ARDS.

Regardless of initiating insult, DAD is the most prevalent histopathological feature of ALI/ARDS and may be an indicator of prognosis [15,16]. The acute exudative phase of ALI/ARDS occurs within hours of the initiating injury event; DAD in this phase results from neutrophilic infiltrates which release enzymes such as elastase that further damage the epithelium and endothelium leading to increased permeability of the alveolar-capillary boundary and lung interstitial and parenchymal edema [17-21]. After several days, DAD is exacerbated to such a degree that denuding of alveolar basement membranes ensues, and cellular debris consisting of hyaline membranes, plasma

*Corresponding author: Deborah E. Sullivan, PhD, Associate Professor, Department of Microbiology and Immunology, 1430 Tulane Avenue, SL-38, New Orleans, LA 70112, USA, Tel: 504988 6690; Fax: 504988 5144; E-mail: dsulliva@ tulane.edu

Received October 05, 2011; Accepted November 10, 2011; Published November 12, 2011

Citation: Bonvillain RW, Zhang S, Eagle ME, Danchuk S, Bunnell BA, et al (2011) Battling Inflammation in Acute Lung Injury and Acute Respiratory Distress Syndrome: Stem Cell-Based Therapy Targeting the Root Cause of Acute Lung Injury. J Pulmonar Respirat Med S2:001. doi:10.4172/2161-105X.S2-001

Copyright: (c) 2011 Bonvillain RW, et al. This is an open-access article distributed under the terms of the Creative Commons Attribution License, which permits unrestricted use, distribution, and reproduction in any medium, provided the original author and source are credited. 
Citation: Bonvillain RW, Zhang S, Eagle ME, Danchuk S, Bunnell BA, et al. (2011) Battling Inflammation in Acute Lung Injury and Acute Respiratory Distress Syndrome: Stem Cell-Based Therapy Targeting the Root Cause of Acute Lung Injury. J Pulmonar Respirat Med S2:001. doi:10.4172/2161-105X.S2-001

Page 2 of 8

proteins, and fibrin collects in the alveolar space. Complement and coagulation pathways are activated, and the damaged tissue releases reactive oxygen and nitrogen species (ROS and RNS, respectively) and a so-called "cytokine storm" consistent with massive escalating inflammation [22]. Both epithelial and endothelial cells contribute to this inflammatory escalation during certain types of ALI including viral infection [23]. Concomitantly, pulmonary blood flow is diminished due to microvascular thrombosis and hypoxia-induced vasoconstriction $[24,25]$. Following these inflammatory pathological changes is a fibroproliferative phase occurring weeks after the initiating injury during which epithelial (alveolar type II) cells and fibroblasts propagate within the intra-alveolar exudates that accumulated during the acute phase. The fibroblasts subsequently differentiate into myofibroblasts, and extracellular matrix (ECM) proteins, predominantly collagens, are secreted within the alveolar space and accumulate throughout the parenchyma leading to marked fibrosis. Alveolar loss results from the increasing cellular mass and ECM deposition within the air space but may be exacerbated without prominent airspace occlusion if alveolar type II cells are damaged by ALI and, therefore, fail to provide sufficient surfactant to prevent alveolar collapse [14]. The lung vasculature also undergoes aberrant smooth muscle proliferation that leads to decreased vascular intraluminal diameter and associated pulmonary hypertension. Uncontrolled, the condition can progress to obliterative endarteritis (complete arteriolar obstruction), further hypoxic injury, and compromised right ventricular function.

Given the multiple etiologies of ALI/ARDS, the heterogeneity of clinical presentation, and co-morbidity associated with indirect ALI and lifestyle-associated risks (smoking, alcohol abuse, obesity, etc.), finding an appropriate course of therapeutic intervention is a substantial challenge. Ideally, treatment should be geared toward preventing the escalation of inflammatory processes at the early onset of disease before development of the devastating morphological changes that occur during the fibroproliferative phase of ARDS. Furthermore, treatments for late-stage disease must account for tissue remodeling and functional loss as a result of progressive lung fibrosis. Current treatment strategies for patients with ARDS/ALI involve general supportive measures combined with focused ventilatory strategies and palliative treatment of the underlying conditions [26]. There are no effective pharmacological therapies for ARDS. ARDS is characterized by an overwhelming inflammatory process followed by fibro-proliferative changes, therefore antiinflammation has been a topic of interest for several years, and recent developments in immunomodulation therapy have generated new insights for treatment of diseases where inflammation is a central pathological feature. Resident macrophages are among the first cells to respond to danger signals in the lung by rapidly producing chemokines and cytokines that recruit polymorphonuclear leukocytes (neutrophils or PMNs) [27]. Therefore, if the initial acute inflammatory response of macrophages can be attenuated, the inflammation cascade may be dampened, thus contributing to the alleviation of ALI. This review will highlight current clinical therapies for ALI/ARDS with specific attention to controlling the root cause of morbidity in this disease -excessive inflammation- and novel pre-clinical cell-based approaches and gene therapy geared toward preventing long-term complications.

\section{Pharmacological anti-inflammatory therapy in ALI}

Corticosteroids have been investigated as a potential treatment for ALI because of their anti-inflammatory properties. Early trials using time-limited high-dose corticosteroids failed to demonstrate a survival benefit [28]. There is some evidence that low-dose corticosteroid treatment can reduce the mortality and morbidity associated with
ALI [29]. However, controversy remains because other studies have provided conflicting data [30]. Other strategies to control inflammation and prevent ALI/ARDS have been proposed such as inhibition of thromboxane A2 synthesis [31], TNF blockers [32], neutrophil elastase inhibitors [33], and anti-oxidants [34]. However, most of these agents failed during clinical trials and did not provide protection to patients suffering from acute bacterial infections. Preclinical animal studies have shown promising results for reducing ALI-associated inflammation using anti-CD40 ligand (a mediator of proinflammatory cytokine production in pulmonary fibroblasts), and anti-IL-8 (a potent chemoattractant for PMNs) antibodies [3537]. Schaefer et al. [38] showed that infusion of fish oil-based lipid emulsions reduced LPS-induced proinflammatory cytokines, alveolar leukocyte transmigration, and protein leakage in a murine ALI model. Another study demonstrated that administration of hesperidin down regulated the expression of pro-inflammatory cytokines and chemokines, reduced the infiltration of activated PMNs in the airways, decreased pulmonary edema, reduced nitrosative stress, and improved lung morphology in a murine ALI model [39]. A more lung-specific anti-inflammatory strategy is needed which can be used in combination with current physical and pharmacological therapies for ALI/ARDS.

\section{Stem cells and anti-inflammation: application to ALI/ARDS}

Mesenchymal stem cells (MSCs) and ALI: Stem cells are gaining increased attention as potential cell-based therapeutic agents for lung diseases. Mesenchymal stem cells (MSCs) are a heterogeneous subset of progenitor cells that have self-renewal and multilineage differentiation capacity [40-42]. In addition to their therapeutic potential for tissue regeneration, MSCs have been shown to possess potent immunomodulatory and immunosuppressive properties in several models $[43,44]$. MSCs can be isolated from many adult tissues (e.g. bone marrow, adipose, umbilical cord, and lung tissue) with high yield and can be expanded easily in vitro. MSCs are often considered to be hypoimmunogenic or immune privileged, since they express low levels of major histocompatibility complex (MHC) class I and II, and do not express of co-stimulatory molecules $[45,46]$. Furthermore, immunodulation by MSCs is not MHC-restricted, making allogeneic treatment possible [47]. Thus, MSCs provide unique opportunities for developing novel treatments for a large array of inherited and acquired diseases. In 2008, the first clinical trial evaluating human mesenchymal stem cells (hMSCs) in a lung disease, chronic obstructive pulmonary disease (COPD), was initiated. Reports from the trial indicate that allogeneic hMSCs significantly decreased systemic inflammation in patients when compared to those receiving placebo, as determined by C-reactive protein. Although the pulmonary function in patients receiving hMSCs was not significantly improved compared to those receiving placebo despite the reduction in inflammation, the results indicate that hMSCs are safe in patients with compromised pulmonary function [48].

Whereas it was originally postulated that the greatest benefit of MSCs in lung repair may be their ability to reconstitute areas of damage by homing to sites of tissue injury, engrafting, and differentiating, it is generally accepted now that, given the low levels of engraftment, MSCs likely contribute to lung protection and repair via paracrine mechanisms [49,50]. An emerging body of data indicates that MSCs elicit immunomodulatory responses in different models of ALI [5153]. Ortiz et al. [54,55] found that mouse bone marrow-derived MSCs improved survival and dampened inflammation when delivered intravenously in a mouse bleomycin model of pulmonary fibrosis; later the same group presented evidence that the immunomodulatory 
Citation: Bonvillain RW, Zhang S, Eagle ME, Danchuk S, Bunnell BA, et al. (2011) Battling Inflammation in Acute Lung Injury and Acute Respiratory Distress Syndrome: Stem Cell-Based Therapy Targeting the Root Cause of Acute Lung Injury. J Pulmonar Respirat Med S2:001. doi:10.4172/2161-105X.S2-001

Page 3 of 8

effects of murine MSCs were mediated, at least in part, by their potent expression of interleukin-1 receptor antagonist (IL-1Ra) and its blockade of the pro-inflammatory cytokines tumor necrosis factor-alpha (TNF- $\alpha$ ) and IL-1. Several groups have investigated the anti-inflammatory effects of MSCs in lung injury induced by intraperitoneal [56] or intrapulmonary [51,52] endotoxin exposure (Escherichia coli lipopolysaccharide, LPS). Xu et al. [56] found that intravenous delivery of syngeneic bone marrow-derived MSCs immediately after intraperitoneal challenge with endotoxin attenuated neutrophil infiltration in the lung and decreased Th1-related cytokines while Th2 cytokines were unchanged. Gupta et al. [51] reported that intrabronchial delivery of mouse bone marrow-derived MSCs to mice 4 hours after intratracheal endotoxin resulted in decreased lung edema and improved survival. This study also showed that bronchoalveolar lavage and plasma from endotoxin-challenged mice treated with MSCs had lower concentrations of TNF- $\alpha$ and macrophage inflammatory protein-2 (MIP-2) and higher concentrations of the anti-inflammatory cytokine IL-10 compared with untreated mice. In a recent publication, we reported that administration of human bone marrow-derived MSCs by oropharyngeal aspiration (OA) to immunocompetent mice 4 hours after intratracheal endotoxin significantly reduced the expression of pro-inflammatory cytokines, neutrophil counts, total protein in bronchoalveolar lavage, and pulmonary edema [52]. Our study demonstrated that xenogeneic bone marrow-derived MSCs recapitulated the observed immunomodulatory effects of syngeneic MSCs [52]. Most recently, lung-derived MSCs (LMSC) isolated from tissue homogenates were investigated for potential therapeutic benefits in ALI [57-59]. Hoffman et al. [58] found that LMSC contribute to repair of elastase-injured lungs (a model of emphysema) to a similar degree as bone marrow-derived MSCs (BMSC); however the LMSC showed a propensity toward extended lung retention time relative to BMSC [59].

Little is known about the mechanisms by which MSCs modulate lung inflammation and repair. The anti-inflammatory effects of mouse MSCs in the lung have been associated with MSC secretion of interleukin 1 receptor antagonist (IL1Ra) [54] and TGF- $\beta 1$ [60]. TNF$\alpha$-induced protein 6 (TNFAIP6/TSG-6) is emerging as a key factor in the immunosuppressive properties of MSCs [61-63]. TSG-6 is a $35 \mathrm{kDa}$, secreted protein produced by many cell types in response to TNF- $\alpha$ and IL-1 $\beta[64,65]$. The anti-inflammatory properties of TSG-6 have been demonstrated in several different models including arthritis, myocardial infarction, and chemical injury to the cornea [62-65]. TSG6 inhibits the inflammatory network of proteases by increasing the inhibitory activity of inter- $\alpha$ inhibitor and bikunin [66]. TSG-6 also specifically binds and sequesters hyaluronan fragments and has been shown to be a potent inhibitor of neutrophil activation and migration, as well as tissue remodeling [67], through upregulation of COX-2 and prostaglandin $\mathrm{D}_{2}$ expression $[67,68]$. We recently demonstrated that MSCs secrete high levels of TSG-6 in response to lung injury in vivo [52]. Using RNA interference we found that expression of TSG6 is largely responsible for the anti-inflammatory effects of MSCs, including reduction in inflammatory cell infiltrates, in the endotoxin model of lung injury and that intratracheal or intravenous delivery of recombinant human TSG-6 (rhTSG-6) reproduces much of the therapeutic benefits of MSCs [52]. The precise mechanism(s) by which TSG-6 protects the lung from acute inflammation is not clear but may not be dependent on localization of MSCs to the lung since intraperitoneal administration of hMSC in our mouse endotoxininduced ALI model also attenuated lung inflammation [52]. Choi et al. [61] recently demonstrated that TSG-6 interacts with the CD44 receptor on resident macrophages to decrease nuclear translocation of NF- $\mathrm{KB}$ and suppress expression of TNF- $\alpha$, IL-6, IL- 8 and CCL2. These results suggest that MSCs, through expression of TSG-6, set up a negative feedback loop to inhibit inflammation and, therefore, may inhibit the development of ALI/ARDS. Lee et al. [53] demonstrated that secretion of keratinocyte growth factor (KGF) was essential for the beneficial effect of hMSCs on alveolar epithelial fluid transport in the ex vivo perfused human lung model challenged with endotoxin. It is evident from these initial findings that MSCs likely employ several mechanisms by which they reduce inflammatory processes. Characterizing these pathways will help to elucidate the precise molecular bases of antiinflammation by MSCs, but studies investigating the synergistic effects of multiple mechanisms are certainly warranted.

iPS Cells and ALI: Induced pluripotent stem (iPS) cells have been a popular focus in stem cell biology since the first report of their creation by Takahasi et al. [69]. Transfection of the factors Oct3/4, Sox2, KiF4, and $c M y c$ under embryonic stem cell (ESC) culture conditions have a re-programming effect on terminally differentiated cells (e.g. skin fibroblasts) such that they acquire characteristics associated with stemness in native stem cells including expression of ESC genes, ESC morphology and growth properties, and tumorigenicity when implanted subcutaneously. A recent study by Yang et al. [70] reported that intravenously delivered iPS cells have a protective effect against ALI when animals are challenged with endotoxin intratracheally. Similar to other studies, including our own using MSCs, iPS cells reduced NFKB-mediated inflammatory responses and suppressed the infiltration of neutrophils into the lungs after LPS challenge. Remarkably, intravenous administration of iPS cell-conditioned media had a similar effect as inoculation with whole cells, suggesting that a great deal of the observed protective effect of iPS cells may be a product of secreted bioactive factors.

\section{Antimicrobial properties of stem cells}

The leading cause of ALI/ARDS is pneumonia resulting from bacterial infection of the lung. Streptococcus pneumoniae, a grampositive bacterium, is the most common cause of community-acquired pneumonia, whereas hospital-acquired pneumonia is most often associated with the Gram-negative Pseudomonas aeruginosa. Bacterial infection of the lung triggers innate inflammatory responses. ALI occurs when this inflammation is uncontrolled resulting in exorbitant neutrophil infiltration, disruption of the pulmonary capillary interface, edema, and respiratory failure. Antibiotics can reduce bacterial load, however they do not provide protection against ALI caused by an overactive immune response [71,72]. Moreover, prior antibiotic treatment greatly increases the likelihood of infection with resistant organisms which markedly worsens mortality and morbidity [73]. Therefore, there is a great need for innovative therapies that target only the misguided activity of the immune system while keeping its protective function intact.

In a recent study by Mei et al. [74] using the cecal ligation and puncture (CLP) sepsis model in mice, murine MSC treatment significantly enhanced bacterial clearance. In addition to downregulation of pro-inflammatory genes, murine MSC treatment led to up-regulation of genes that promote phagocytosis and bacterial killing in macrophages, monocytes, natural killer (NK) cells, and antigenpresenting cells (APCs). Consistent with these results, murine MSC treatment reduced colony forming unit (CFU) counts in the spleens of mice that had undergone CLP. Direct phagocytosis of Escherichia coli or Staphylococcus aureus by MSCs was slight and did not increase after in vitro co-culture with macrophages; however, peritoneal and splenic $\mathrm{CD} 11 \mathrm{~b}+$ cells isolated from CLP-induced septic mice showed increased 
Citation: Bonvillain RW, Zhang S, Eagle ME, Danchuk S, Bunnell BA, et al. (2011) Battling Inflammation in Acute Lung Injury and Acute Respiratory Distress Syndrome: Stem Cell-Based Therapy Targeting the Root Cause of Acute Lung Injury. J Pulmonar Respirat Med S2:001. doi:10.4172/2161-105X.S2-001

Page 4 of 8

phagocytic activity, in vivo. MSC treatment increased the survival rate of CLP-injured mice in the absence and presence of antibiotic therapy; these data suggest that MSC-mediated attenuation of ALI may be due to a combination of immunomodulatory and anti-microbial effects. It has also been recently reported that, in mouse models of $E$. coliinduced pneumonia, intratracheally-delivered human bone marrowand umbilical cord-derived MSCs promoted bacterial clearance and attenuated ALI, respectively $[75,76]$.

Krasnodembskaya et al. [75] reported that human cathelicidin antimicrobial peptide-18 (hCAP-18/LL-37) mediates the direct inhibition of bacterial growth by human MSCs. LL-37 is an hCAP-18 cleaveage product of $4 \mathrm{kDa}$ and is a pro-inflammatory peptide that has been linked to prevention of bacterial infections and host defense against microbes, particularly in the lung where it is expressed by lung epithelial cells and submucosal glands [77,78]. LL-37 is known to be expressed by PMNs, keratinocytes, and epithelial cells and can function as a chemotactic signal for neutrophils, monocytes, mast cells, and T-cells [79]. Additionally, LL-37 binds and neutralizes LPS, stimulates degranulation of mast cells, modifies transcriptional activity in macrophages, and participates in wound healing by promoting vascularization and re-epithelialization of healing skin [77,80]. It has been shown that LL-37 administration can protect against E.coli or CLP-induced sepsis in rats [81]. Interestingly, LL-37 has been shown to promote recruitment of MSCs via the formyl peptide receptor (FPLR1) and alter the immunomodulatory properties of MSCs, perhaps by acting, in part, as a potential ligand for the toll-like receptor-4 (TLR4) [82,83]. In addition to LL-37, the tryptophan catabolizing enzyme indoleamine 2,3-dioxygenase (IDO) has been linked to the antimicrobial activity of human MSCs, but not murine MSCs which do not express IDO [84]. IDO-mediated antimicrobial activity of human MSCs is not limited to bacteria but is also effective against protozoan parasites and viruses [84]. It is apparent that MSCs are both directly and indirectly involved in antimicrobial activity and that this ability is applicable to treating microbial complications in the lung potentially using either allogeneic or autologous cells.

\section{Gene-modified MSCs}

Early studies in adult stem cell biology suggested that MSCs could be genetically altered to enhance their homing to injured sites, particularly toward sites of infection; however, there has been much difficulty in achieving engraftment rates substantial enough to achieve therapeutic benefit $[49,85-87]$. For this reason, the use of gene modification in stem cells has somewhat shifted in focus toward using the cells as vehicles for delivering therapeutic agents. In light of the numerous proteins and pathways involved in lung protective mechanisms that have been identified, many gene modification strategies have been developed to enhance the ability of MSCs to combat lung injury. Several of these strategies have targeted inflammatory processes.

Keratinocyte growth factor (KGF): KGF has been extensively studied as a key element in lung development, growth, and repair [8891]. After lung injury, KGF stimulates the proliferation of alveolar epithelial cells and helps to facilitate alveolar epithelial fluid movement [92-94]. When used as a prophylactic measure, treatment with KGF has been shown to lessen the degree of radiation- and bleomycininduced pulmonary fibrosis and improve survival [95]. Haddad et al. [96] showed that delivery of exogenous KGF preceding bone marrow transplant in a rat model of idiopathic pneumonia suppressed T-cellmediated macrophage activation and release of pro-inflammatory cytokines. In a novel approach to delivery of KGF to the lung, Aguilar et al. [97] transduced bone marrow-derived MSCs and hematopoietic stem cells (HSCs) with a lentiviral vector carrying an inducible (TetOn) KGF expression cassette; they showed that both MSC and HSC cell constructs were protective against bleomycin-induced fibrosis, but KGF-expressing HSCs, in particular, greatly attenuated histological damage typically associated with this model. This work supports the use of cell-based vehicles for delivery of therapeutic agents but also highlights the important fact that cell-type specificity is equally important when designing these types of strategies.

Angiopoietin-1 (ANGPT-1): ANGPT-1 ligand and its endothelialspecific receptor tyrosine kinase, Tie2, initiate pathways involved in angiogenesis and maturation of neovasculature [98]. ANGPT-1 has also been shown to be a protective factor which promotes the integrity of the vasculature by preventing endothelial permeability and apoptosis [99-101]. Leukocyte adhesion to the endothelium is suppressed by ANGPT-1, as is the expression of endothelial cell-surface adhesion molecules; moreover, in an experimental model of ALI, neutrophil infiltration, capillary leakage, and lung edema were associated with a down-regulation of ANGPT-1 [102-104]. McCarter et al. [105] employed a skin fibroblast-based cellular ANGPT-1 delivery system in a rat endotoxin model of ALI and showed marked improvement in lung inflammation and injury. Xu et al. [106] were the first to use MSCs as vehicles for delivering ANGPT-1 in an animal (mouse) model of ALI. In their experiments, either MSC or ANGPT-1 alone showed substantial reduction in lung neutrophil infiltrates or TNF- $\alpha$ expression, but MSCs expressing ANGPT-1 significantly reduced these parameters even further, implying that there is a synergistic effect of MSC and ANGPT-1 in the context of preventing ALI-induced inflammation.

Inhibition of CCL2: The monocyte chemotactic protein-1 (MCP1), also referred to as CCL2, is a pro-inflammatory cytokine that recruits monocytes, T-cells, dendritic cells, and fibrocytes to areas of inflammation via CCR2 receptors [107]. Elevated levels of CCL2 are associated with heightened disease severity in patients with ALI/ARDS, and CCL2 has been implicated in the development of lung fibrosis in gene knockout mouse models [108-113]. Mutagenesis analysis uncovered a deletion mutant of CCL2, 7ND, that functions as a dominant negative inhibitor of CCL2 $[114,115]$. In a very recent report, Saito et al. [116] expressed the 7ND mutant in adipose-derived MSCs from $\mathrm{C} 57 \mathrm{BL} / 6 \mathrm{~N}$ mice using a lentiviral vector carrying the construct to stably transfect the cells. The CCL2-inhibited MSCs were then delivered intravenously to mice with bleomycin-induced pulmonary fibrosis. Their results demonstrated that CCL2 knockdown MSCs substantially reduced cell infiltrates in the lung, facilitated maintenance of weight, reduced plasma IL- 6 and IL- $1 \beta$, and improved survival relative to sham-treated controls.

Taken together, these cell-based techniques provide excellent evidence that gene-modified stem cells have the potential to function as novel therapeutic agents in the fight against inflammation in ALI/ARDS. Further investigation is warranted, however, to test the efficiency and safety of individual approaches as well as possible synergistic effects of combined methods.

\section{Summary/Conclusions}

To improve outcome in patients suffering from ALI/ARDS, it is imperative to prevent permanent lung damage (i.e. fibrosis) from occurring by early intervention in disease progression. Since inflammation is the initiating event through which the morbidity of ALI/ARDS develops, fighting inflammation early on is the best possible way to quench the onset of lung failure. Currently, stem-cell based therapy holds great promise for providing this necessary clinical intervention. 
Citation: Bonvillain RW, Zhang S, Eagle ME, Danchuk S, Bunnell BA, et al. (2011) Battling Inflammation in Acute Lung Injury and Acute Respiratory Distress Syndrome: Stem Cell-Based Therapy Targeting the Root Cause of Acute Lung Injury. J Pulmonar Respirat Med S2:001. doi:10.4172/2161-105X.S2-001

Page 5 of 8

Early observations of engraftment of mesenchymal stem cells in the lung was a promising development in the fields of stem cell biology and lung disease; however, there has been no development towards improving the disappointingly low number of cells which can actually accomplish this feat. The discovery that stem cells have endogenous immunomodulatory and anti-microbial capabilities is sparking a robust push in the research community to uncover the mechanisms by which the cells can potentially protect against infection and inflammation and develop novel therapeutic strategies using stem cells. While there is an increasing amount of data suggesting that a large portion of the immunosuppressive effect of stem cells is mediated through paracrine mechanisms, more work is needed to elucidate the molecular components of this effect and the pathways through which they act. Identification of these paracrine factors and pathways will likely suggest strategies to improve the therapeutic potential of stem cells for treating ALI/ARDS and guide the development of cell-free therapies that have the potential to maintain a ready supply of therapeutic agents without the need to culture stem cells on-demand. In addition, the combination of cell and gene therapy that has been demonstrated to provide additive therapeutic benefits significantly expands the potential application of stem cell based therapy for ALI/ARDS.

Preclinical animal models of ALI/ARDS treated with cellbased therapies have been promising; however there are significant challenges that must be overcome before human clinical trials of stemcell therapy for ALI/ARDS can begin. First, more research is needed to identify the optimal stem cell source, dose, route of delivery and timing of stem cell delivery in order to achieve the most efficient and effective treatment. Second, it is critical to understand the mechanisms integral to the therapeutic effects of stem cells in ALI/ARDS so that the human physiological response can be accurately predicted. Third, the lack of proper standardization and characterization of cell preparations is a serious impediment to the correlation of results from preclinical and early clinical studies. Finally, wide-ranging toxicology studies are required to increase our confidence in the safety of cellular therapies. The lack of human models of ALI has been a major limitation in overcoming these challenges. Recently, Lee et al. [117] employing an in vitro model of ALI/ARDS that incorporated an ex vivo human lung injured by endotoxin while being ventilated and perfused with human blood, demonstrated that human MSCs injected into the pulmonary circulation improved the clearance of fluid from the alveolar spaces. Although this model is limited by the short-term viability of the explanted lung and does not recapitulate the full inflammatory process, it provides valuable evidence that stem cell therapies hold great promise in treating human ALI/ARDS.

\section{Acknowledgements}

This work was supported by the National Heart, Lung, and Blood Institute (NIH) T-32 program grant number 5T32HL007973-07 and The Tulane Center for Stem Cell Research and Regenerative Medicine. The authors would like to thank Dr. Aline M. Betancourt for critical review of this manuscript.

\section{References}

1. Bernard GR, Artigas A, Brigham KL, Carlet J, Falke K, et al. (1994) The American-European Consensus Conference on ARDS. Definitions, mechanisms, relevant outcomes, and clinical trial coordination. Am J Respir Crit Care Med. 149: 818-824.

2. Murray JF, Matthay MA, Luce JM, Flick MR (1988) An expanded definition of the adult respiratory distress syndrome. Am Rev Respir Dis 138: 720-723.

3. No author listed (1992) American College of Chest Physicians/Society of Critical Care Medicine Consensus Conference: definitions for sepsis and organ failure and guidelines for the use of innovative therapies in sepsis. Crit Care Med 20: 864-874.
4. Pollack MM, Patel KM, Ruttimann UE (1996) PRISM III: an updated Pediatric Risk of Mortality score. Crit Care Med 24: 743-752.

5. Slater, A, Shann F ANZICS Paediatric Study Group (2004) The suitability of the Pediatric Index of Mortality (PIM), PIM2, the Pediatric Risk of Mortality (PRISM), and PRISM III for monitoring the quality of pediatric intensive care in Australia and New Zealand. Pediatr Crit Care Med 5: 447-454.

6. Shann F, Pearson G, Slater A, Wilkinson K (1997) Paediatric index of mortality (PIM): a mortality prediction model for children in intensive care. Intensive Care Med. 23: 201-207.

7. Trachsel D, McCrindle BW, Nakagawa S, Bohn D (2005) Oxygenation index predicts outcome in children with acute hypoxemic respiratory failure. Am J Respir Crit Care Med 172: 206-211.

8. Ferguson ND, Davis AM, Slutsky AS, Stewart TE (2005) Development of a clinical definition for acute respiratory distress syndrome using the Delph technique. J Crit Care 20: 147-154

9. Hudson LD, Milberg JA, Anardi D, Maunder RJ (1995) Clinical risks fo development of the acute respiratory distress syndrome. Am J Respir Crit Care Med 151: 293-301.

10. Hammer J (2001) Acute lung injury: pathophysiology, assessment and current therapy. Paediatr Respir Rev 2: 10-21.

11. Raghavendran K, Pryhuber GS, Chess PR, Davidson BA, Knight PR, et al. (2008) Pharmacotherapy of acute lung injury and acute respiratory distress syndrome. Curr Med Chem 15 : 1911-1924.

12. Krafft $P$, Fridrich P, Pernerstorfer T, Fitzgerald RD, Koc D, et al. (1996) The acute respiratory distress syndrome: definitions, severity and clinical outcome. An analysis of 101 clinical investigations. Intensive Care Med 22: 519-529.

13. Doyle RL, Szaflarski N, Modin GW, Wiener-Kronish JP, Matthay MA (1995) Identification of patients with acute lung injury. Predictors of mortality. Am J Respir Crit Care Med 152: 1818-1824.

14. Ware LB Matthay MA (2000) The acute respiratory distress syndrome. N Eng J Med 342: 1334-1349.

15. Esteban A, Fernandez-Segoviano P, Frutos-Vivar F, Aramburu JA, Nájera L, et al. (2004) Comparison of clinical criteria for the acute respiratory distress syndrome with autopsy findings. Ann Intern Med 141: 440-445

16. Quesnel C, Piednoir P, Gelly J, Nardelli L, Garnier M, et al. (2011) Alveolar fibrocyte percentage is an independent predictor of poor outcome in patients with acute lung injury. Crit Care Med [Epub ahead of print].

17. Johnson MD, Widdicombe JH, Allen L, Barbry P, Dobbs LG (2002) Alveolar epithelial type I cells contain transport proteins and transport sodium, supporting an active role for type I cells in regulation of lung liquid homeostasis. Proc Nat Acad Sci U S A 99: 1966-1971.

18. Matthay MA, Wiener-Kronish JP (1990) Intact epithelial barrier function is critical for the resolution of alveolar edema in humans. Am Rev Respir Dis 142 1250-1257.

19. Matthay MA, Fukuda N, Frank J, Kallet R, Daniel B, et al. (2000) Alveolar epithelial barrier. Role in lung fluid balance in clinical lung injury. Clin Chest Med 21: 477-490.

20. Sartori C, Matthay MA, Scherrer U (2001) Transepithelial sodium and wate transport in the lung. Major player and novel therapeutic target in pulmonary edema. Adv Exp Med Biol 502: 315-338.

21. Sachs UJ (2011) Recent insights into the mechanism of transfusion-related acute lung injury. Curr Opin Hematol 18: 436-442.

22. Knight PR, Davidson BA, Nader ND, Helinski JD, Marschke CJ, et al. (2004) Progressive, severe lung injury secondary to the interaction of insults in gastric aspiration. Exp Lung Res 30: 535-557.

23. Teijaro JR, Walsh KB, Cahalan S, Fremgen DM, Roberts E, et al. (2011) Endothelial Cells are Central Orchestrators of Cytokine Amplification during Influenza Virus Infection. Cell 146: 980-991.

24. Frazziano G, Moreno L, Moral-Sanz J, Menendez C, Escolano L, et al. (2011) Neutral sphingomyelinase, NADPH oxidase and reactive oxygen species. Role in acute hypoxic pulmonary vasoconstriction. J Cell Physiol 226: 2633-2640.

25. Hedelin P, Kylhammar D, Rådegran G (2011) Dual endothelin receptor blockade with tezosentan markedly attenuates hypoxia-induced pulmonary vasoconstriction in a porcine model. Acta Physiol (Oxf) Epub ahead of print. 
Citation: Bonvillain RW, Zhang S, Eagle ME, Danchuk S, Bunnell BA, et al. (2011) Battling Inflammation in Acute Lung Injury and Acute Respiratory Distress Syndrome: Stem Cell-Based Therapy Targeting the Root Cause of Acute Lung Injury. J Pulmonar Respirat Med S2:001. doi:10.4172/2161-105X.S2-001

26. Dushianthan A, Grocott MP, Postle AD, Cusack R (2011) Acute respiratory distress syndrome and acute lung injury. Postgrad Med J 87: 612-622.

27. Soehnlein O, Lindbom L (2010) Phagocyte partnership during the onset and resolution of inflammation. Nat Rev Immunol 10: 427-439.

28. Peter JV, John P, Graham PL, Moran JL, George IA, et al. (2008) Corticosteroids in the prevention and treatment of acute respiratory distress syndrome (ARDS) in adults: meta-analysis. BMJ 336: 1006-1009.

29. Marik PE, Meduri GU, Rocco PR, Annane D (2011) Glucocorticoid treatment in acute lung injury and acute respiratory distress syndrome. Crit Care Clin 27: 589-607.

30. Tang BM, Craig JC, Eslick GD, Seppelt I, McLean AS (2009) Use of corticosteroids in acute lung injury and acute respiratory distress syndrome: a systematic review and meta-analysis. Crit Care Med 37: 1594-1603.

31. No authors listed (2000) Ketoconazole for early treatment of acute lung injury and acute respiratory distress syndrome: a randomized controlled trial. The ARDS Network. JAMA 283: 1995-2002.

32. No authors listed (2002) Randomized, placebo-controlled trial of lisofylline for early treatment of acute lung injury and acute respiratory distress syndrome. Crit Care Med 30: 1-6.

33. Zeiher BG, Artigas A, Vincent JL, Dmitrienko A, Jackson K, et al. (2004) Neutrophil elastase inhibition in acute lung injury: results of the STRIVE study. Crit Care Med. 32: 1695-1702.

34. Adhikari N, Burns KE, Meade MO (2004) Pharmacologic treatments for acute respiratory distress syndrome and acute lung injury: systematic review and meta-analysis. Treat Respir Med 3: 307-328.

35. Adawi A, Zhang Y, Baggs R, Finkelstein J, Phipps RP (1998) Disruption of the CD40-CD40 ligand system prevents an oxygen-induced respiratory distress syndrome. Am J Pathol 152: 651-657.

36. Yokoi K, Mukaida N, Harada A, Watanabe Y, Matsushima K (1997) Prevention of endotoxemia-induced acute respiratory distress syndrome-like lung injury in rabbits by a monoclonal antibody to IL-8. Lab Invest 76: 375-384.

37. Presneill JJ, Harris T, Stewart AG, Cade JF, Wilson JW (2002) A randomized phase II trial of granulocyte-macrophage colony-stimulating factor therapy in severe sepsis with respiratory dysfunction. Am J Respir Crit Care Med 166: 138-143.

38. Schaefer MB, Ott J, Mohr A, Bi MH, Grosz A, et al. (2007) Immunomodulation by $n-3$ - versus $n-6$-rich lipid emulsions in murine acute lung injury--role of platelet-activating factor receptor. Crit Care Med 35: 544-554.

39. Yeh CC, Kao SJ, Lin CC, Wang SD, Liu CJ, et al. (2007) The immunomodulation of endotoxin-induced acute lung injury by hesperidin in vivo and in vitro. Life Sci 80: $1821-1831$

40. Prockop DJ (1997) Marrow Stromal Cells as Stem Cells for Nonhematopoietic Tissues. Science 276: 71-74.

41. Pittenger MF, Mackay AM, Beck SC, Jaiswal RK, Douglas R, et al. (1999) Multilineage potential of adult human mesenchymal stem cells. Science 284 143-147.

42. Uccelli A, Moretta L, Pistoia V (2008) Mesenchymal stem cells in health and disease. Nat Rev Immunol 8: 726-736.

43. Ripoll CB, Flaat M, Klopf-Eiermann J, Fisher-Perkins JM, Trygg CB, et al (2011) Mesenchymal lineage stem cells have pronounced anti-inflammatory effects in the twitcher mouse model of Krabbe's disease. Stem Cells 29: 67-77.

44. Bunnell BA, Betancourt AM, Sullivan DE (2010) New concepts on the immune modulation mediated by mesenchymal stem cells. Stem Cell Res Ther 1: 34 .

45. Nauta AJ, Fibbe WE (2007) Immunomodulatory properties of mesenchymal stromal cells. Blood 110: 3499-3506.

46. Patel SA, Sherman L, Munoz J, Rameshwar P (2008) Immunological properties of mesenchymal stem cells and clinical implications. Arch Immunol Ther Exp (Warsz) 56: 1-8.

47. Aggarwal S, Pittenger MF (2005) Human mesenchymal stem cells modulate allogeneic immune cell responses. Blood. 105: 1815-1822.

48. Osiris Therapeutics Reports interim data for COPD stem cell study [Online] http://investor.osiris.com/releases.cfm?Year=\&ReleasesType=\&DisplayPa ge=5. Accessed on: 30 Sep 2011

49. Viswanathan A, Painter RG, Lanson NA Jr, Wang G (2007) Functional expression of $\mathrm{N}$-formyl peptide receptors in human bone marrow-derived mesenchymal stem cells. Stem Cells 25: 1263-1269.

50. Rojas M, Xu J, Woods CR, Mora AL, Spears W, et al. (2005) Bone marrowderived mesenchymal stem cells in repair of the injured lung. Am J Respir Cell Mol Biol 33: 145-152.

51. Gupta N, Su X, Popov B, Lee JW, Serikov V, et al. (2007) Intrapulmonary delivery of bone marrow-derived mesenchymal stem cells improves survival and attenuates endotoxin-induced acute lung injury in mice. J Immunol. 179 1855-1863.

52. Danchuk S, Ylostalo JH, Hossain F, Sorge R, Ramsey A, et al. (2011) Human multipotent stromal cells attenuate lipopolysaccharide-induced acute lung injury in mice via secretion of tumor necrosis factor-alpha-induced protein 6.Stem Cell Res Ther 2: 27.

53. Lee JW, Fang X, Gupta N, Serikov V, Matthay MA (2009) Allogeneic human mesenchymal stem cells for treatment of $E$. coli endotoxin-induced acute lung injury in the ex vivo perfused human lung. Proc Natl Acad Sci USA 106: 1635716362.

54. Ortiz LA, Dutreil M, Fattman C, Pandey AC, Torres G, et al. (2007) Interleukin 1 receptor antagonist mediates the antiinflammatory and antifibrotic effect of mesenchymal stem cells during lung injury. Proc Natl Acad Sci U S A 104 11002-11007.

55. Ortiz LA, Gambelli F, McBride C, Gaupp D, Baddoo M, et al. (2003) Mesenchyma stem cell engraftment in lung is enhanced in response to bleomycin exposure and ameliorates its fibrotic effects. Proc Natl Acad Sci U S A 100: 8407-8411.

56. Xu J, Woods CR, Mora AL, Joodi R, Brigham KL, et al. (2007) Prevention of endotoxin-induced systemic response by bone marrow-derived mesenchymal stem cells in mice. Am J Physiol Lung Cell Mol Physiol 293: L131-L141.

57. Summer R, Fitzsimmons K, Dwyer D, Murphy J, Fine A (2007) Isolation of an adult mouse lung mesenchymal progenitor cell population. Am J Respir Cell Mol Biol 37: 152-159.

58. Hoffman AM, Paxson JA, Mazan MR, Davis AM, Tyagi S, et al. (2011) LungDerived Mesenchymal Stromal Cell Post-Transplantation Survival, Persistence, Paracrine Expression, and Repair of Elastase-Injured Lung. Stem Cells Dev 20: $1779-1792$

59. Ingenito, EP, Tsai, L, Murthy, S, Tyagi, S, Mazan, M, et al. (2011) Autologous lung-derived mesenchymal stem cell transplantation in experimental emphysema. Cell Transplant [Epub ahead of print]

60. Nemeth K, Keane-Myers A, Brown JM, Metcalfe DD, Gorham JD, et al. (2010) Bone marrow stromal cells use TGF-beta to suppress allergic responses in a mouse model of ragweed-induced asthma. Proc Natl Acad Sci U S A 107: 5652-5657.

61. Choi H, Lee RH, Bazhanov N, Oh JY, Prockop DJ (2011) Anti-inflammatory protein TSG-6 secreted by activated MSCs attenuates zymosan-induced mouse peritonitis by decreasing TLR2/NF-KB signaling in resident macrophages. Blood 118: 330-338

62. Lee RH, Pulin AA, Seo MJ, Kota DJ, Ylostalo J, et al. (2009) Intravenous hMSCs improve myocardial infarction in mice because cells embolized in lung are activated to secrete the anti-inflammatory protein TSG-6. Cell Stem Cell 5: 54-63.

63. Oh JY, Roddy GW, Choi H, Lee RH, Ylostalo JH, et al. (2010) Anti-inflammatory protein TSG-6 reduces inflammatory damage to the cornea following chemical and mechanical injury. Proc Natl Acad Sci U S A 107: 16875-16880.

64. Milner CM, Higman VA, Day AJ (2006) TSG-6: a pluripotent inflammatory mediator? Biochem Soc Trans 34: 446-450.

65. Wisniewski HG, Vilcek J (2004) Cytokine-induced gene expression at the crossroads of innate immunity, inflammation and fertility: TSG-6 and PTX3/ TSG-14. Cytokine Growth Factor Rev 15: 129-146.

66. Forteza R, Casalino-Matsuda SM, Monzon ME, Fries E, Rugg MS, et al. (2007) TSG-6 potentiates the antitissue kallikrein activity of inter-alpha-inhibitor through bikunin release. Am J Respir Cell Mol Biol 36: 20-31.

67. Milner CM, Day AJ (2003) TSG-6: a multifunctional protein associated with inflammation. J Cell Sci 116: 1863-1873.

68. Mindrescu C, Le J, Wisniewski HG, Vilcek J (2005) Up-regulation of cyclooxygenase-2 expression by TSG-6 protein in macrophage cell line. Biochem Biophys Res Commun 330: 737-745.

69. Takahashi K, Yamanaka S (2006) Induction of pluripotent stem cells from 
Citation: Bonvillain RW, Zhang S, Eagle ME, Danchuk S, Bunnell BA, et al. (2011) Battling Inflammation in Acute Lung Injury and Acute Respiratory Distress Syndrome: Stem Cell-Based Therapy Targeting the Root Cause of Acute Lung Injury. J Pulmonar Respirat Med S2:001. doi:10.4172/2161-105X.S2-001

mouse embryonic and adult fibroblast cultures by defined factors. Cell 126: 663-676.

70. Yang KY, Shih HC, How CK, Chen CY, Hsu HS, et al. (2011) IV Delivery of Induced Pluripotent Stem Cells Attenuates Endotoxin-induced Acute Lung Injury in Mice. Chest 140: 1243-1253.

71. Davidson R, Péloquin L (2002) Anti-inflammatory effects of the macrolides. J Otolaryngol 31: S38-S40.

72. Woo PC, Pau S, Yuen K (2002) Macrolides as immunomodulatory agents. Curr Med Chem Anti inflamm Anti Allergy Agents 1: 131-141.

73. Dreyfuss D, Ricard JD (2005) Acute lung injury and bacterial infection. Clin Chest Med 26: 105-112.

74. Mei SH, Haitsma JJ, Dos Santos, CC Deng, Y Lai PF, et al. (2010) Mesenchymal stem cells reduce inflammation while enhancing bacterial clearance and improving survival in sepsis. Am J Respir Crit Care Med 182: 1047-1057.

75. Krasnodembskaya A, Song Y, Fang X, Gupta N, Serikov V, et al. (2010) Antibacterial effect of human mesenchymal stem cells is mediated in part from secretion of the antimicrobial peptide LL-37. Stem Cells 28: 2229-2238.

76. Kim ES, Chang YS, Choi SJ, Kim JK, Yoo HS, et al. (2011) Intratracheal transplantation of human umbilical cord blood-derived mesenchymal stem cells attenuates Escherichia coli-induced acute lung injury in mice. Respir Res 12: 108.

77. Zanetti M (2004) Cathelicidins, multifunctional peptides of the innate immunity J Leukoc Biol 75: 39-48.

78. Rogan MP, Geraghty P, Greene CM, O’Neill SJ, Taggart CC, et al. (2006) Antimicrobial proteins and polypeptides in pulmonary innate defence. Respir Res 7: 29.

79. Yang, D, Chertov, O and Oppenheim, JJ. (2001) Participation of mammalian defensins and cathelicidins in antimicrobial immunity: receptors and activities of human defensins and cathelicidin (LL-37). J Leukoc Biol 69: 691-697.

80. Larrick JW, Hirata M, Balint RF, Lee J, Zhong J, et al. (1995) Human CAP18: a novel antimicrobial lipopolysaccharide-binding protein. Infect Immun 63: 12911297.

81. Cirioni O, Giacometti A, Ghiselli R, Bergnach C, Orlando F, et al. (2006) LL-37 protects rats against lethal sepsis caused by gram-negative bacteria. Antimicrob Agents Chemother 50: 1672-1679.

82. Tomchuck SL, Zwezdaryk KJ, Coffelt SB, Waterman RS, Danka ES, et al. (2008) Toll-like receptors on human mesenchymal stem cells drive their migration and immunomodulating responses. Stem Cells 26: 99-107.

83. Coffelt SB, Marini FC, Watson K, Zwezdaryk KJ, Dembinski JL, et al. (2009) The pro-inflammatory peptide LL-37 promotes ovarian tumor progression through recruitment of multipotent mesenchymal stromal cells. Proc Natl Acad Sci U S A 106: 3806-3811.

84. Meisel R, Brockers S, Heseler K, Degistirici O, Bülle H, et al. (2011) Human but not murine Multipotent mesenchymal stromal cells exhibit broad-spectrum antimicrobial effector function mediated by indoleamine 2,3- dioxygenase. Leukemia 25: 648-654

85. Zhao F, Zhang YF, Liu YG, Zhou JJ, Li ZK, et al. (2008) Therapeutic effects of bone marrow-derived mesenchymal stem cells engraftment on bleomycininduced lung injury in rats. Transplant Proc 40: 1700-1705.

86. Yan X, Liu Y, Han Q, Jia M, Liao L, et al. (2007) Injured microenvironment directly guides the differentiation of engrafted Flk-1(+) mesenchymal stem cell in lung. Exp Hematol 35: 1466-1475.

87. Muller-Ehmsen J, Krausgrill B, Burst V, Schenk K, Neisen UC, et al. (2006) Effective engraftment but poor mid-term persistence of mononuclear and mesenchymal bone marrow cells in acute and chronic rat myocardial infarction. J Mol Cell Cardiol 41: 876-884

88. Atabai K, Ishigaki M, Geiser T, Ueki I, Matthay MA, et al. (2002) Keratinocyte growth factor can enhance alveolar epithelial repair by nonmitogenic mechanisms. Am J Physiol Lung Cell Mol Physiol 283: L163-L169.

89. Oswari J, Matthay MA, Margulies SS (2001) Keratinocyte growth factor reduces alveolar epithelial susceptibility to in vitro mechanical deformation. Am J Physiol Lung Cell Mol Physiol. 281: L1068-L1077.

90. Verghese GM, McCormick-Shannon K, Mason RJ, Matthay MA (1998) Hepatocyte growth factor and keratinocyte growth factor in the pulmonary edema fluid of patients with acute lung injury. Biologic and clinical significance. Am J Respir Crit Care Med 158: 386-394.
91. Ware LB, Matthay MA (2002) Keratinocyte and hepatocyte growth factors in the lung: roles in lung development, inflammation, and repair. Am J Physiol Lung Cell Mol Physiol 282: L924-L940.

92. Galiacy S, Planus E, Lepetit H, Fereol S, Laurent V, et al. (2003) Keratinocyte growth factor promotes cell motility during alveolar epithelial repair in vitro. Exp Cell Res 283: 215-229.

93. Matthay MA, Fukuda N, Frank J, Kallet R, Daniel B, et al. (2000) Alveola epithelial barrier. Role in lung fluid balance in clinical lung injury. Clin Chest Med 21: 477-490.

94. Wang Y, Folkesson HG, Jayr C, Ware LB, Matthay MA (1999) Alveolar epithelial fluid transport can be simultaneously upregulated by both KGF and beta-agonist therapy. J Appl Physiol 87: 1852-1860.

95. Yi ES, Williams ST, Lee H, Malicki DM, Chin EM, et al. (1996) Keratinocyte growth factor ameliorates radiation- and bleomycin-induced lung injury and mortality. Am J Pathol 149: 1963-1970.

96. Haddad IY, Panoskaltsis-Mortari A, Ingbar DH, Resnik ER, Yang S, et al. (1999) Interactions of keratinocyte growth factor with a nitrating species after marrow transplantation in mice. Am J Physiol 277: L391-L400.

97. Aguilar S, Scotton CJ, McNulty K, Nye E, Stamp G, et al. (2009) Bone marrow stem cells expressing keratinocyte growth factor via an inducible lentivirus protects against bleomycin-induced pulmonary fibrosis. PLoS One 4: e8013.

98. Davis S, Aldrich TH, Jones PF, Acheson A, Compton DL, et al. (1996) Isolation of angiopoietin-1, a ligand for the TIE2 receptor, by secretion-trap expression cloning. Cell 87: 1161-1169.

99. Suri C, Jones PF, Patan S, Bartunkova S, Maisonpierre PC, et al. (1996) Requisite role of angiopoietin-1, a ligand for the TIE2 receptor, during embryonic angiogenesis. Cell 87: 1171-1180.

100.Papapetropoulos A, Garcia-Cardena G, Dengler TJ, Maisonpierre PC Yancopoulos GD, et al. (1999) Direct actions of angiopoietin-1 on human endothelium: evidence for network stabilization, cell survival, and interaction with other angiogenic growth factors. Lab Invest 79: 213-223.

101. Kwak HJ, So JN, Lee SJ, Kim I, Koh GY (1999) Angiopoietin-1 is an apoptosis survival factor for endothelial cells. FEBS Lett 448: 249-253.

102. Kim I, Moon SO, Park SK, Chae SW, Koh GY (2001) Angiopoietin-1 reduces VEGF-stimulated leukocyte adhesion to endothelial cells by reducing ICAM-1, VCAM-1, and E-selectin expression. Circ Res 89: 477-479.

103. Pizurki L, Zhou Z, Glynos K, Roussos C, Papapetropoulos A (2003) Angiopoietin-1 inhibits endothelial permeability, neutrophil adherence and IL-8 production. Br J Pharmacol 139: 329-336.

104. Karmpaliotis D, Kosmidou I, Ingenito EP, Hong K, Malhotra A, et al. (2002) Angiogenic growth factors in the pathophysiology of a murine model of acute lung injury. Am J Physiol Lung Cell Mol Physiol 283: L585-L595.

105. McCarter SD, Mei SH, Lai PF, Zhang QW, Parker CH, et al. (2007) Cell-based angiopoietin-1 gene therapy for acute lung injury. Am J Respir Crit Care Med 175: $1014-1026$

106. Xu J, Qu J, Cao L, Sai Y, Chen C, et al. (2008) Mesenchymal stem cell-based angiopoietin-1 gene therapy for acute lung injury induced by lipopolysaccharide in mice. J Pathol 214: 472-481.

107.Deshmane SL, Kremlev S, Amini S, Sawaya BE (2009) Monocyte chemoattractant protein-1 (MCP-1): an overview. J Interferon Cytokine Res 29: 313-326.

108. Rosseau S, Hammerl P, Maus U, Walmrath HD, Schutte H, et al. (2000) Phenotypic characterization of alveolar monocyte recruitment in acute respiratory distress syndrome. Am J Physiol Lung Cell Mol Physiol 279 : L25-L35.

109. Goodman RB, Strieter RM, Martin DP, Steinberg KP, Milberg JA, et al. (1996) Inflammatory cytokines in patients with persistence of the acute respiratory distress syndrome. Am J Respir Crit Care Med 154: 602-611.

110.Lin WC, Lin CF, Chen CL, Chen CW, Lin YS (2010) Prediction of outcome in patients with acute respiratory distress syndrome by bronchoalveolar lavage inflammatory mediators. Exp Biol Med (Maywood) 235: 57-65.

111. Moore BB, Kolodsick JE, Thannickal VJ, Cooke K, Moore TA, et al. (2005) CCR2-mediated recruitment of fibrocytes to the alveolar space after fibrotic injury. Am J Pathol 166: 675-684.

112. Moore BB, Paine R 3rd, Christensen PJ, Moore TA, Sitterding S, et al. (2001) Protection from pulmonary fibrosis in the absence of CCR2 signaling. J Immunol 167: 4368-4377. 
Citation: Bonvillain RW, Zhang S, Eagle ME, Danchuk S, Bunnell BA, et al. (2011) Battling Inflammation in Acute Lung Injury and Acute Respiratory Distress Syndrome: Stem Cell-Based Therapy Targeting the Root Cause of Acute Lung Injury. J Pulmonar Respirat Med S2:001. doi:10.4172/2161-105X.S2-001

Page 8 of 8

113. Gharaee-Kermani M, McCullumsmith RE, Charo, IF Kunkel SL, Phan SH (2003) CC-chemokine receptor 2 required for bleomycin-induced pulmonary fibrosis. Cytokine 24: 266-276.

114.Zhang Y, Rollins BJ (1995) A dominant negative inhibitor indicates that monocyte chemoattractant protein 1 functions as a dimer. Mol Cell Biol 15 $4851-4855$.

115.Zhang YJ, Rutledge BJ, Rollins BJ (1994) Structure/activity analysis of human monocyte chemoattractant protein-1 (MCP-1) by mutagenesis. Identification of a mutated protein that inhibits MCP-1-mediated monocyte chemotaxis. J Biol Chem 269: 15918-15924.

116. Saito S, Nakayama T, Hashimoto N, Miyata Y, Egashira K, et al. (2011) Mesenchymal Stem Cells Stably Transduced with a Dominant-Negative Inhibitor of CCL2 Greatly Attenuate Bleomycin-Induced Lung Damage. Am J Pathol 179: 1088-1094.

117. Lee JW, Fang X, Gupta N, Serikov V, Matthay MA (2009) Allogeneic human mesenchymal stem cells fortreatment of $E$. coli endotoxin-induced acute lung injury in the ex vivo perfused human lung. Proc Natl Acad Sci USA 106: 16357-16362.

This article was originally published in a special issue, Acute Lung Injury handled by Editor(s). Dr. Yuanlin Song, Fudan University, China 